\title{
Exploring Green Hotel Competitive Strategies by Using the Hybrid Method for Complex Data Analysis
}

\author{
Chia-Huei Wu \\ Department of Hotel Management and Culinary Creativity, Minghsin University of Science and Technology, \\ Hsinchu 30401, Taiwan \\ Correspondence should be addressed to Chia-Huei Wu; chiahuei530@gmail.com
}

Received 11 March 2021; Revised 29 March 2021; Accepted 8 June 2021; Published 16 June 2021

Academic Editor: Adnan Maqsood

Copyright (c) 2021 Chia-Huei Wu. This is an open access article distributed under the Creative Commons Attribution License, which permits unrestricted use, distribution, and reproduction in any medium, provided the original work is properly cited.

Green hotels emphasize safety, health, and environmental friendliness and advocate for green operations, green consumption, environmental protection, and the reasonable consumption of resources in operations. In short, environmental protection and moderate resource consumption are underscored. The literature on green hotel criteria and competitive strategies has two shortcomings. Some studies assume the independence of each criterion; these criteria are not mutually influential or causally related. By contrast, other studies set equal weights for all criteria. The present study explored the criteria and competitive strategies of green hotels by combining the importance-performance analysis (IPA) and the Decision-Making Trial and Evaluation Laboratory (DEMATEL) method into the IPA-DEMATEL model.

\section{Introduction}

Hotels provide their guests with comfort and convenience. Among tourism-related industries, the hotel industry has the highest energy and water consumption. Regular hotels' substantial consumption of energy, water, and various products, including nonrecyclable products, causes considerable environmental problems and produces excessive waste. Furthermore, energy and water consumption pollutes both air (e.g., in the form of $\mathrm{CO}_{2}$ emissions) and water [1].

Green hotels emphasize safety, health, and environmental friendliness and advocate for green operations, green consumption, environmental protection, and the reasonable consumption of resources in operations. Guests stay in environmentally friendly rooms, and dining services also adhere to these concepts [2]. The longstanding societal ignorance or negligence of environmental issues is by no means unintentional. Environmental protection requires investment and the input of social resources. In today's society, these investments may take the form of relevant measures that have been developed and implemented in response to demands for environmental protection. Amid the pervasiveness and exacerbation of environmental pollution, the capacity to act is crucial. In adopting environmentally friendly practices and incorporating environmental management into hotel operations management, green hotels embody the concepts of environmental protection, resource conservation, health, and safety; implement green management and resource conservation measures; and promote green consumption with regard to reasonable resource use [3].

The concept of green hotels originated from a German green label organization in the 1980s, initially for the purpose of academic discussion. Other implications of "green" include sustainability, environmental friendliness, and not harming the environment $[4,5]$. According to Gan [6], being green implies reducing negative environmental impacts through action (e.g., recycling and green consumption). Green consumption, which has received international attention in recent years, has raised consumer awareness of environmental issues. Governments around the world have introduced mechanisms concerning environmentally or ecologically friendly hotels. For example, Green Seal, a USbased global nonprofit organization, has a certification program for green hotels, and in 1998, the Hotel Association of Canada established the Green Leaf Eco-Rating Program, 
advocating for the Green Leaf Eco Standard developed by the United Nations Educational, Scientific and Cultural Organization [6].

The hotel industry has both direct and indirect impacts on the environment. Despite their high number, hotels are generally scattered around a city, providing direct service, because they have relatively smaller scales of operation. This reduces the social visibility of their environmental impacts even as they expand in scale. As external problems, environmental issues do not receive considerable corporate attention [7]. Therefore, it is difficult for governments to establish regulations or adopt measures for their management or control. With global economic growth and rising national incomes, leisure lifestyles have grown in popularity, prompting an increase in the tourist population, stimulating the tourism industry. Pollution generated by this industry has attracted attention in recent years, with consumers becoming more aware of the importance of environmental protection. Thus, green hotels have become a new industrial trend.

The present paper discusses the criteria and competitive strategies of green hotels. The importance-performance analysis (IPA) and the Decision-Making Trial and Evaluation Laboratory (DEMATEL) method were combined into the IPA-DEMATEL model. IPA was first performed on the green performance of case hotel. Subsequently, the DEMATEL method was used to determine the degrees of influence and identify the relationships among green performance criteria. Finally, green competitive strategies were proposed for the case hotel.

\section{Literature Review}

2.1. Green Hotels. As mentioned, green hotels prioritize safety, health, and environmental friendliness. In this context, safety refers to an emphasis on public safety and food safety, and health refers to the provision of products and services that benefit consumers both physically and psychologically. As for environmental friendliness, green hotels strive to reduce environmental pollution, conserve energy, and lower the amount of resources consumed in the operational process. A clear consensus regarding the definition of green hotels has yet to be reached. Internationally, the terms green hotels, ecoefficient hotels, and environmentally friendly hotels are essentially interchangeable in that they indicate that environmental management is involved. The present study defines green hotels as hotels that endeavor to effectively utilize energy, water, and raw materials in providing services characterized by environmental friendliness $[8,9]$.

Green hotels seek opportunities for corporate growth in the market and actively take corresponding measures. To offer suggestions and determine directions of development for green hotels to capitalize on market opportunities and avoid market threats, we performed a theoretical analysis [10].

Market opportunities and strengths of green hotels are listed as follows:

(1) Lower procurement costs for resources and energy usage
(2) Lower waste processing costs

(3) Opportunities to attract new green consumer groups

(4) Provision of a safe and comfortable work environment

(5) Reduction of employee risks concerning health or safety problems

(6) Improvement of employee morale, which reinforces the provision of high-quality service

(7) Improvement in relationships between the hotel and neighboring communities

(8) Improvement of market image

Hotels that do not apply appropriate environmental protection measures may sustain the following market losses:

(1) Loss of market shares attributable to a damaged market image

(2) Loss of attractiveness

(3) Risk of legal consequences caused by regulation violations amid the passing of stricter environmental protection laws

(4) Reduced employee loyalty leading to a higher turnover rate

(5) Lack of preparedness leading to an inability to respond to increased operational costs

Manaktola and Jauhari identified low pollution generation, energy conservation, and the use of regenerated and recycled materials as the main principles under which green hotels operate [10]. In general, the development and operations of the hotel industry hinder sustainable development because they involve the high consumption of natural resources, generating considerable amounts of waste and leading to serious water pollution. In recent years, hotels around the world have paid appreciable attention to topics linked to environmental protection, adopting relevant measures to reverse the current trend of environmental pollution. Some hotels seek to fulfill corporate social responsibility by establishing such measures; thus, green hotels have become an international trend [10]. To reduce their negative environmental impacts, green hotels adopt environmentally responsible practices (ERPs), which may constitute adherence to sustainable environmental standards, regulations, the optimization of environmental protection practices, the use of environment protection seals and environment management systems, and the consideration of environmental criteria [11]. Enterprises that implement ERPs may obtain the following benefits: cost efficiency, resource conservation, enhanced customer retention rates and customer loyalty, and improved employee morale, all of which enhance their corporate image. Studies have discussed various ERPs within the hotel industry [12].

2.2. Green Hotel Evaluation. Amid the rise in environmental awareness in recent years, the concept of green hotels has become popular in foreign countries. Because each country 
holds different evaluation standards for green hotels, various assessment standards have been developed. The Green Hotel Association has identified the Green Leaf Eco-Rating Program launched in 1998 by the Hotel Association of Canada as the most mature global assessment standard for green hotels. In total, 14 criteria are involved. Green hotels meeting $5,8,10,12$, and 14 criteria are given scores of $1,2,3,4$, and 5 leaves, respectively. Green Key, an international eco-label established in Denmark, takes 11 criteria into account. To obtain this label, leisure organizations (e.g., green hotels) must conform to strict environmental requirements and ensure that their operational methods and concepts comply with emission and waste reduction standards $[13,14]$. Excellent customer service is also a necessity. The standards developed by the US nonprofit Green Seal require green hotels to meet six criteria within specific guidelines. According to their performance, hotels are given ratings of gold, silver, or bronze. China's national standard for green hotels mandates the fulfillment of basic requirements, which is followed by assessment that is based on six main criteria. The maximum score is 300 ; hotels achieving scores of $\geq 270$, $269-240,239-210,209-180$, and $179-160$ points are rated as 5-, 4-, 3-, 2-, and 1-leaf hotels, respectively $[15,16]$.

We compiled the green hotel evaluation standards and management strategies obtained from the literature review and classified them into the following dimensions.

2.2.1. Energy Conservation. The energy efficiency of green hotels, which do not constitute the majority in Taiwan's hotel industry: each green hotel can conserve energy through its own methods. These methods aim to reduce energy consumption and waste (e.g., of resources) and attain coexistence with the environment. This dimension comprises the following criteria: (1) water conservation practices, (2) electricity conservation practices, and (3) energy conservation in air conditioning.

2.2.2. Waste Reduction. Reduction of generated waste and hazardous materials: green hotels strive to provide highquality service and promote sustainable development under the principle of environmental friendliness. Regular hotels generate a considerable amount of environmental pollution; thus, waste reduction is critical in green hotels. This dimension comprises the following criteria: (1) garbage classification and recycling, (2) the prohibition of disposable products and engagement in waste reduction efforts, and (3) the use of recycled products.

2.2.3. Health. The internal and external environment and the effect of hotel facilities on the environment and on consumer health: the rise in health awareness in Taiwan has intensified the national focus on health-related topics, meaning that green hotels must promote health and safety through their facilities now more than ever. Therefore, green hotel managers must thoroughly consider criteria related to environmental protection and consumer health. This dimension comprises the following criteria: (1) the procurement of green products, (2) environmental maintenance and protection, and (3) the use of organic food products.

2.2.4. Marketing. Marketing strategies: this refers to how green hotels promote their environmental friendliness, teach consumers the relevance of going green as leisure organizations, and use effective word-of-mouth advertising to improve brand image. This dimension comprises the following criteria: (1) brand awareness, (2) brand image, and (3) overall service quality. Table 1 presents the classification of the 12 criteria into four dimensions.

\section{Research Methods}

Studies on the criteria and competitive strategies of green hotels have two shortcomings. Some studies assume the independence of each criterion; these criteria are not mutually influential or causally related; others set equal weights for all criteria. The present discussion was centered on sustainability. IPA and the DEMATEL method were combined to create the IPA-DEMATEL model. The importance and performance of case hotels were determined through IPA. Subsequently, the DEMATEL method was used to calculate the degree of influence and identify the relationships among the green criteria. Finally, a competitive strategy was proposed for the case hotel.

3.1. IPA. In IPA, whose basic framework was developed by Martilla and James for practical applications, mean importance and performance scores are plotted in a two-dimensional plane, on the vertical and horizontal axes, respectively (Figure 1).

IPA considers four quadrants, which are defined as follows [17]:

(1) Keep up the good work: representing high importance and high performance

(2) Concentrate here: representing high importance and low performance

(3) Low priority: representing low importance and low performance

(4) Possible overkill: representing low importance and high performance

According to the plotting of the criteria, managers can optimize resource allocation and enhance prioritization to increase customer satisfaction. As a simple technique for evaluating the strengths and weaknesses of criteria and developing methods for improvement in the pursuit of customer satisfaction, IPA has been widely applied in various fields [18].

3.2. Decision-Making Trial and Evaluation Laboratory. Originally developed at the Battelle Memorial Institute Geneva Research Centre, the DEMATEL method was used by Gabus and Fontela to resolve various complex global 
TABLE 1: Evaluation dimensions and criteria of green hotels.

Dimension
(A) Energy conservation

(B) Waste reduction

(C) Health

(D) Marketing

\section{Criteria}

(A1) Water conservation practices

(A2) Electricity conservation practices

(A3) Energy conservation in air conditioning

(B1) Garbage classification and recycling

(B2) Prohibition of disposable products and engagement in waste reduction efforts

(B3) Use of recycled products

(C1) Green product procurement

(C2) Environmental protection and maintenance

(C3) Use of organic food products

(D1) Brand awareness

(D2) Brand image

(D3) Overall service quality

\begin{tabular}{l|l} 
Concentrate here & Keep up the good work \\
\hline Low priority & Performance \\
\hline & Possible overkill
\end{tabular}

FIGURE 1: The four quadrants of importance-performance analysis (IPA).

problems, including issues concerning racism, hunger, environmental protection, and energy use $[19,20]$.

The DEMATEL approach uses a matrix to determine intercriteria relationships and degrees of influence. The DEMATEL framework and calculation procedures in this study are detailed as follows [21-25].

3.2.1. Define the Criteria and Propose a Scale of Measurement. By using various tools and methods, such as brainstorming, expert opinions, and literature review, list and define criteria that may influence the performance of the complex system. Subsequently, establish a scale for measuring the relationships and degrees of influence between criteria.

3.2.2. Establish the Direct-Relation Matrix. After seeking expert opinion, the $n$ criteria that influence a complex system can be used to form a direct-relation matrix $X(n \times n)$, where $X_{i j}$ represents the degree of influence of $i$ on $j$ and the diagonal elements are set as 0 .

$$
X=\left[\begin{array}{cccc}
0 & x_{12} & \cdots & x_{1 n} \\
x_{21} & 0 & \cdots & x_{2 n} \\
\vdots & \vdots & \ddots & \vdots \\
x_{n 1} & x_{n 2} & \cdots & 0
\end{array}\right]
$$

3.2.3. Construct the Normalized Direct-Relation Matrix. To construct the normalized direct-relation matrix, Lin and $\mathrm{Wu}$ [26], used row vectors and row maximums as the normalization standard as follows:

$$
\text { compute } \lambda=\frac{1}{\operatorname{Max}_{1 \leq i \leq n}\left(\sum_{j=1}^{n} x_{i j}\right)} \text {. }
$$

And then multiply the direct-relation matrix $X$ by $\lambda$ to obtain the normalized direct-relation matrix $N$ :

$$
N=\lambda X
$$

3.2.4. Construct the Total-Relation Matrix. Having obtained the normalized direct-relation matrix $N$, the identity matrix $I$ is then used to establish the total-relation matrix $T$, also known as the direct-indirect matrix.

$$
T=\lim _{k \longrightarrow \infty}\left(N+N^{2}+\cdots+N^{k}\right)=N(I-N)^{-1} .
$$

3.2.5. Calculate the Influence Degree and the Dependence Degree. After obtaining $T$, we can calculate the influence degree and dependence degree of each criterion. Let $t_{i j}$ represent the criteria in $T$, where $i, j=1,2, \ldots, n$. $D_{i}$, the sum of row $I$, represents the total degree of influence of criterion $i . R_{j}$ is the sum of column $j$ and represents the total degree of dependence on criterion $i . D_{i}$ and $R_{j}$ obtained from $T$ contain direct and indirect influences.

$$
\begin{aligned}
& D_{i}=\sum_{j=1}^{n} t_{i j}, \quad i=1,2, \ldots, n, \\
& R_{j}=\sum_{i=1}^{n} t_{i j}, \quad j-1,2, \ldots, n .
\end{aligned}
$$

3.2.6. Plotting the Cause-and-Effect Diagram. Given $k=i=j=1,2, \ldots, n$, let $\left(D_{k}+R_{k}\right)$ be the prominence, representing the combined degree of influence and degree of dependence $[27,28]$. This value indicates the degree of centrality of criterion $k$ in the problem. Next, define 
$\left(D_{k}-R_{k}\right)$ as the relation, which refers to the difference between the degrees of influence and dependence. If the relation, which indicates the degree of causality of criterion $k$ in the problem, is a positive value, then the criterion belongs in the cause group. Conversely, if the relation is negative, then the criterion belongs in the effect group $[26,29,30]$.

In the cause-and-effect matrix diagram, $\left(D_{k}+R_{k}\right)$ and $\left(D_{k}-R_{k}\right)$ are the horizontal and vertical axes, respectively. Through the use of figures, the diagram simplifies complex relationships into easily understandable structures. Decision-makers can reference the position of each criterion to determine whether they belong in the cause or effect group, as well as the degrees of influence and dependence. Problems can be resolved through suitable decisions accordingly [31-33].

A positive and negative $\left(D_{k}-R_{k}\right)$ value indicates that criterion $k$ falls in the cause group and the effect group, respectively. A greater $\left(D_{k}+R_{k}\right)$ value indicates that criterion $k$ has greater degrees of influence and dependence. Based on the $\left(D_{k}+R_{k}\right)$ and $\left(D_{k}-R_{k}\right)$ coordinates of $k$, criterion $k$ is classified into the following four categories:

(a) A positive $\left(D_{k}-R_{k}\right)$ and a large $\left(D_{k}+R_{k}\right)$ : the criterion belongs in the cause group and is a factor driving problem resolution

(b) A positive $\left(D_{k}-R_{k}\right)$ and a small $\left(D_{k}+R_{k}\right)$ : the criterion is independent and influences few other criteria

(c) A negative $\left(D_{k}-R_{k}\right)$ and a large $\left(D_{k}+R_{k}\right)$ : the criterion is a core problem that must be solved. However, because the criterion falls in the effect group, direct improvements cannot be made

(d) A negative value of $\left(D_{k}-R_{k}\right)$ and a small value of $\left(D_{k}+R_{k}\right)$ : the criterion is independent and is influenced by few other criteria

\section{Results and Discussion}

4.1. Questionnaire Design. The case hotel was company T, which is among the top 10 hotels in Taiwan. The performance of company $T$ as a green hotel was evaluated, and the results serve as a reference for improvement.

Questionnaires involving IPA and the DEMATEL method were used. Regarding the IPA questionnaire, expert opinion was sought on the importance and performance of company $T$ on each mentioned criterion. Each of the 12 items was scored on a 7 -point Likert scale (from $7=$ very important and to $1=$ not at all important). Subsequently, the DEMATEL questionnaire was administered to the same panel of experts to obtain their opinions on the criteria. The items were also scored on a 7 -point Likert scale $(6=$ the most significant level of influence; $0=$ no influence; ranks between 6 and 0 were scored sequentially according to the level of significance). The two questionnaires were distributed between February 22 and March 12, 2021. The respondents comprised 15 experts: 7 hotel managers, 5 university professors, and 3 officials at principal government agencies, respectively. The author personally visited, explained the questionnaire content, and administered the questionnaire to each participant. The valid return rate for both questionnaires was $100 \%$.

As mentioned, the 12 criteria of green hotels were classified into 4 dimensions (Table 1). The energy conservation dimension comprises (1) water conservation practices, (2) electricity conservation practices, and (3) energy conservation in air conditioning. The waste reduction dimension comprises (1) garbage classification and recycling, (2) the prohibition of disposable products and engagement in waste reduction efforts, and (3) the use of recycled products. The health dimension comprises (1) green product procurement, (2) environmental protection and maintenance, (3) and the use of organic food products. The marketing dimension comprises (1) brand awareness, (2) brand image, and (3) overall service quality.

\subsection{Results and Discussion}

4.2.1. IPA Results. The mean values of importance (5.76) and performance (5.71) were used as the standard coordinates for determining the performance of each criterion (Table 2).

The IPA revealed that, in the "keep up the good work" quadrant, there were criteria B1, B2, C1, C3, and D3 (garbage classification and recycling, prohibition of disposable products and engagement in waste reduction efforts, green product procurement, use of organic food products, and overall service quality, resp.). In other words, company $T$ should maintain its performance in these areas for effective word-of-mouth marketing.

In the "concentrate here" quadrant, there were criteria B3, C2, and D2 (use of recycled products, environmental protection and maintenance, and brand image, resp.). Company $T$ must channel its resources into improving its performance in these areas to increase its competitiveness in green management.

Company $T$ did not exhibit satisfactory performance on criterion A2 (electricity conservation practices) or criterion D1 (brand awareness), both in the "low priority" quadrant. Because these criteria have low importance, they should be given the least priority, to be focused on only when the company has an abundance or overabundance of resources. In the "possible overkill" quadrant, indicative of outstanding performance on matters of low importance, there were criteria $\mathrm{A} 1$ and $\mathrm{A} 3$ (water conservation practices and energy conservation in air conditioning, resp.). Efforts devoted to these criteria do not yield additional benefits to the company. Therefore, managers should consider allocating company resources to other criteria (Table 2).

4.2.2. DEMATEL Results. Table 3 presents the results from the questionnaires in the form of the initial direct-relation matrix $X$. Specifically, the mean scores of the 15 experts were calculated and rounded to one decimal place. These results were then used to generate the initial direct-relation matrix, which consists of 144 squares. After the elimination of the 12 diagonal elements, 132 elements remained. 
TABLE 2: Importance and performance of green hotel criteria.

\begin{tabular}{lcccc}
\hline No. & Item & Importance & Performance & Competitive strategy \\
\hline a1 & Water conservation practices & 5.2 & 5.9 & Possible overkill \\
a2 & Electricity conservation practices & 5.3 & 5.6 & Low priority \\
a3 & Energy conservation in air conditioning & 5.5 & 6.1 & Possible overkill \\
b1 & Classifying and recycling garbage & 6.1 & 5.8 & Keep up the good work \\
b2 & Prohibition of disposable products and engagement in waste reduction & 6.0 & 5.9 & Keep up the good work \\
b3 & efforts & 6.0 & 5.2 & Concentrate here \\
c1 & Use of recycled products & 6.1 & 5.9 & Keep up the good work \\
c2 & Green product procurement & 5.9 & 5.3 & Concentrate here \\
c3 & Environmental protection and maintenance & 5.9 & 5.9 & Keep up the good work \\
d1 & Use of organic food products & 5.6 & 5.5 & Low priority \\
d2 & Brand awareness & 5.9 & 5.6 & Concentrate here \\
d3 & Brand image & 6.1 & 6.0 & Keep up the good work \\
Mean & Overall service quality & 5.76 & 5.71 & \\
\hline
\end{tabular}

TABle 3: The initial direct-relation matrix $X$.

\begin{tabular}{lcccccccccccc}
\hline Criteria & a1 & a2 & a3 & b1 & b2 & b3 & c1 & c2 & c3 & d1 & d2 & d3 \\
\hline a1 & 0 & 1.4 & 1.5 & 1.1 & 0.7 & 2.5 & 1.4 & 1.7 & 1.5 & 1.4 & 2.1 & 1.8 \\
a2 & 1.3 & 0 & 1.2 & 1.4 & 1.8 & 3.1 & 1.2 & 1.4 & 1.7 & 1.5 & 1.6 & 1.3 \\
a3 & 1.9 & 1.5 & 0 & 1.9 & 1.2 & 2.8 & 1.7 & 1.4 & 1.7 & 1.3 & 1.1 & 1.7 \\
b1 & 1.1 & 1.4 & 1.5 & 0 & 1.4 & 1.2 & 1.2 & 1.2 & 2.9 & 1.5 & 2.2 & 3.3 \\
b2 & 1.4 & 1.6 & 1.4 & 2.5 & 0 & 2.6 & 1.5 & 1.3 & 1.8 & 2.4 & 2.2 & 2.8 \\
b3 & 2.3 & 2.8 & 2.6 & 2.7 & 2.5 & 0 & 2.1 & 3.5 & 2.4 & 1.4 & 2.5 & 2.6 \\
c1 & 2.4 & 2.5 & 3.5 & 2.6 & 2.7 & 2.2 & 0 & 4.7 & 3.1 & 5.5 & 3.5 & 3.7 \\
c2 & 2.3 & 2.2 & 2.1 & 2.5 & 3.3 & 4.4 & 3.6 & 0 & 4.3 & 4.2 & 4.4 & 4.9 \\
c3 & 2.8 & 2.6 & 1.2 & 1.8 & 2.5 & 1.5 & 1.6 & 3.3 & 0 & 3.2 & 3.4 & 3.5 \\
d1 & 1.7 & 1.4 & 2.4 & 1.9 & 2.1 & 2.2 & 2.5 & 2.1 & 2.8 & 0 & 4.4 & 3.1 \\
d2 & 2.3 & 2.5 & 3.1 & 4.3 & 3.2 & 2.6 & 2.8 & 4.2 & 4.4 & 5.2 & 0 & 4.6 \\
d3 & 3.4 & 3.5 & 2.8 & 3.7 & 4.3 & 4.6 & 3.7 & 3.1 & 3.1 & 4.4 & 5.2 & 0 \\
\hline
\end{tabular}

Subsequently, the row vectors and row maximums were used as the normalization standard, with $\lambda$ denoting the reciprocal of the maximum row sum. In equation (2), the direct-relation matrix is multiplied by $\lambda$, and the influence coefficients are rounded to two decimal places to obtain the normalized direct-relation matrix $N$ (Table 4).

Equations (3) and (4) were used to construct the totalrelation matrix $T$. The total-relation criteria matrix is acquired in Table 5.

The $D_{i}$ value for each column and the $R_{j}$ value for each row were calculated using equations (5) and (6), after which the prominence $(D+R)$ and relation $(D-R)$ were obtained. The total influence given and received on dimensions and criteria is summarized in Table 6. Figure 2 shows the plot of the 12 criteria, with the prominence and relation as the $x$ and $y$ coordinates, respectively.

Table 6 and Figure 2 reveal the following relations and influences between the 12 criteria.

(1) High relation and high prominence: C1, C2, D2, and D3 (green product procurement, environmental protection and maintenance, brand image, and overall service quality, resp.). These four criteria belong in the cause group and influence other criteria, suggesting that they constitute factors driving problem resolution.
(2) High relation and low prominence: no criteria were found in this category.

(3) Low relation and high prominence: B3, C3, and D1 (use of recycled products, use of organic food products, and brand awareness, resp.). These three criteria are in the effect group, meaning that they are influenced by other criteria. Although they require improvement, they cannot be directly improved because they are in the effect group.

(4) Low relation and low prominence: A1, A2, A3, B1, and B2 (water conservation practices, electricity conservation practices, energy conservation in air conditioning, garbage classification and recycling, and prohibition of disposable products and engagement in waste reduction efforts, resp.). These five criteria are influenced by other criteria, but not to a great extent, suggesting that they are relatively independent.

Criteria C1, C2, D2, and D3 (green product procurement, environmental protection and maintenance, brand image, overall service quality, resp.) exhibit high relation and high prominence. They constitute key criteria that influence other criteria. Through improvements to these criteria, core problems can be resolved and the company's performance on other criteria can be improved.

4.2.3. IPA-DEMATEL Results. The IPA revealed that criteria $\mathrm{B} 1, \mathrm{~B} 2, \mathrm{C} 1, \mathrm{C} 3$, and D3 (garbage classification and recycling, prohibition of disposable products and engagement in waste reduction efforts, green product procurement, use of organic food products, and overall service quality) were in the "keep up the good work" quadrant. Company $T$ should maintain its advantage with regard to these criteria. The DEMATEL analysis classified criteria C1 and D3 as being in the highrelation, high-prominence category; thus, they belong in the cause group. Accordingly, company $T$ should focus on these two criteria and continue investing resources to maintain its competitive advantage and enhance both its green performance and its performance on other criteria. By contrast, criteria B1, B2, and C3 are relatively independent of other 
TABLE 4: The normalized direct-relation matrix $T$.

\begin{tabular}{lcccccccccccc}
\hline Criteria & $\mathrm{a} 1$ & $\mathrm{a} 2$ & $\mathrm{a} 3$ & $\mathrm{~b} 1$ & $\mathrm{~b} 2$ & $\mathrm{~b} 3$ & $\mathrm{c} 1$ & $\mathrm{c} 2$ & $\mathrm{c} 3$ & $\mathrm{~d} 1$ & $\mathrm{~d} 2$ & $\mathrm{~d} 3$ \\
\hline $\mathrm{a} 1$ & 0.00 & 0.03 & 0.04 & 0.03 & 0.02 & 0.06 & 0.03 & 0.04 & 0.04 & 0.03 & 0.05 & 0.04 \\
a2 & 0.03 & 0.00 & 0.03 & 0.03 & 0.04 & 0.07 & 0.03 & 0.03 & 0.04 & 0.04 & 0.04 & 0.03 \\
a3 & 0.05 & 0.04 & 0.00 & 0.05 & 0.03 & 0.07 & 0.04 & 0.03 & 0.04 & 0.03 & 0.03 & 0.04 \\
b1 & 0.03 & 0.03 & 0.04 & 0.00 & 0.03 & 0.03 & 0.03 & 0.03 & 0.07 & 0.04 & 0.05 & 0.08 \\
b2 & 0.03 & 0.04 & 0.03 & 0.06 & 0.00 & 0.06 & 0.04 & 0.03 & 0.04 & 0.06 & 0.05 & 0.07 \\
b3 & 0.06 & 0.07 & 0.06 & 0.06 & 0.06 & 0.00 & 0.05 & 0.08 & 0.06 & 0.03 & 0.06 & 0.06 \\
c1 & 0.06 & 0.06 & 0.08 & 0.06 & 0.06 & 0.05 & 0.00 & 0.11 & 0.07 & 0.13 & 0.08 & 0.09 \\
c2 & 0.06 & 0.05 & 0.05 & 0.06 & 0.08 & 0.11 & 0.09 & 0.00 & 0.10 & 0.10 & 0.11 & 0.12 \\
c3 & 0.07 & 0.06 & 0.03 & 0.04 & 0.06 & 0.04 & 0.04 & 0.08 & 0.00 & 0.08 & 0.08 & 0.08 \\
d1 & 0.04 & 0.03 & 0.06 & 0.05 & 0.05 & 0.05 & 0.06 & 0.05 & 0.07 & 0.00 & 0.11 & 0.07 \\
d2 & 0.06 & 0.06 & 0.07 & 0.10 & 0.08 & 0.06 & 0.07 & 0.10 & 0.11 & 0.12 & 0.00 & 0.11 \\
d3 & 0.08 & 0.08 & 0.07 & 0.09 & 0.10 & 0.11 & 0.09 & 0.07 & 0.07 & 0.11 & 0.12 & 0.00 \\
\hline
\end{tabular}

TABLE 5: The total-relation criteria matrix TC.

\begin{tabular}{|c|c|c|c|c|c|c|c|c|c|c|c|c|c|}
\hline Criteria & a1 & $\mathrm{a} 2$ & a3 & b1 & $\mathrm{b} 2$ & b3 & $\mathrm{cl}$ & $\mathrm{c} 2$ & $\mathrm{c} 3$ & $\mathrm{~d} 1$ & $\mathrm{~d} 2$ & $\mathrm{~d} 3$ & $D i$ \\
\hline a1 & 0.06 & 0.10 & 0.10 & 0.10 & 0.09 & 0.14 & 0.10 & 0.12 & 0.12 & 0.12 & 0.14 & 0.13 & 1.30 \\
\hline $\mathrm{a} 2$ & 0.09 & 0.06 & 0.09 & 0.10 & 0.11 & 0.15 & 0.09 & 0.11 & 0.12 & 0.12 & 0.12 & 0.12 & 1.29 \\
\hline a3 & 0.11 & 0.10 & 0.07 & 0.12 & 0.10 & 0.14 & 0.10 & 0.11 & 0.12 & 0.12 & 0.12 & 0.13 & 1.33 \\
\hline b1 & 0.10 & 0.11 & 0.11 & 0.08 & 0.11 & 0.12 & 0.10 & 0.11 & 0.16 & 0.13 & 0.15 & 0.17 & 1.45 \\
\hline b2 & 0.11 & 0.12 & 0.11 & 0.15 & 0.09 & 0.16 & 0.11 & 0.12 & 0.14 & 0.16 & 0.16 & 0.17 & 1.60 \\
\hline b3 & 0.15 & 0.16 & 0.16 & 0.17 & 0.17 & 0.12 & 0.15 & 0.19 & 0.18 & 0.17 & 0.19 & 0.20 & 2.00 \\
\hline $\mathrm{c} 1$ & 0.18 & 0.19 & 0.21 & 0.21 & 0.21 & 0.21 & 0.13 & 0.26 & 0.24 & 0.30 & 0.26 & 0.27 & 2.67 \\
\hline c2 & 0.19 & 0.19 & 0.19 & 0.22 & 0.23 & 0.27 & 0.22 & 0.17 & 0.27 & 0.29 & 0.29 & 0.30 & 2.84 \\
\hline c3 & 0.16 & 0.16 & 0.13 & 0.16 & 0.17 & 0.16 & 0.14 & 0.19 & 0.13 & 0.21 & 0.22 & 0.22 & 2.05 \\
\hline d1 & 0.14 & 0.13 & 0.15 & 0.16 & 0.16 & 0.17 & 0.16 & 0.17 & 0.19 & 0.14 & 0.24 & 0.21 & 2.02 \\
\hline $\mathrm{d} 2$ & 0.19 & 0.20 & 0.21 & 0.25 & 0.23 & 0.23 & 0.20 & 0.26 & 0.27 & 0.30 & 0.20 & 0.30 & 2.84 \\
\hline $\mathrm{d} 3$ & 0.22 & 0.22 & 0.21 & 0.25 & 0.26 & 0.28 & 0.23 & 0.24 & 0.25 & 0.30 & 0.32 & 0.21 & 2.98 \\
\hline$R j$ & 1.70 & 1.74 & 1.73 & 1.96 & 1.92 & 2.16 & 1.75 & 2.06 & 2.19 & 2.35 & 2.40 & 2.43 & \\
\hline
\end{tabular}

criteria. In other words, they have little influence on other criteria; nor are they easily influenced by other criteria.

The "concentrate here" quadrant contained criteria B3, C2, and D2 (use of recycled products, environmental protection and maintenance, and brand image, resp.). Company $T$ should channel its resources into improving its performance on these criteria to improve its competitiveness in green management. Subsequent DEMATEL analysis classified criteria C2 and D2 as being in the high-relation, high-prominence category; thus, they belong in the cause group. This suggests that these two criteria critically affect other criteria; they constitute factors driving problem resolution. Company $T$ should immediately concentrate resources to resolve problems concerning its promotion of environmental protection and maintenance, as well as its brand image. Otherwise, its green performance will fall below industry standards, lagging behind that of its competitors. The location of criterion B3 (use of recycled products) in the high-relation, low-prominence category suggests that it influences few other criteria and holds little influence overall, and that it is relatively independent.
The IPA also indicated that criteria A2 and D1 (electricity conservation practices and brand awareness, resp.), on which company $T$ underperformed, were in the "low priority" quadrant. These criteria are relatively independent; they have little influence on and are not easily influenced by other criteria. Therefore, company $T$ is advised to give them the least priority, focusing on them only when the company has an abundance or overabundance of resources.

Company $T$ demonstrated excellent performance on criteria A1 and A3 (water conservation practices and energy conservation in air conditioning), both of which are in the "possible overkill" quadrant, meaning that efforts in these areas do not necessarily confer additional benefits. These two criteria fall in the low-relation, low-prominence category, suggesting that they are relatively independent of other criteria and do not require the investment of a considerable amount of resources.

On the basis of the IPA-DEMATEL results, the competitive strategies of company $T$ were comprehensively analyzed, and specific recommendations were made. The current green performance and competitive strategies of company $T$ are compiled in Table 7. 
TABLE 6: Results on prominence and relation from the DEMATEL analysis.

\begin{tabular}{lcccc}
\hline Criteria & $D$ & $R$ & $D+R$ & $D-R$ \\
\hline a1 & 1.30 & 1.70 & 3.00 & -0.40 \\
a2 & 1.29 & 1.74 & 3.03 & -0.44 \\
a3 & 1.33 & 1.73 & 3.06 & -0.39 \\
b1 & 1.45 & 1.96 & 3.42 & -0.52 \\
b2 & 1.60 & 1.92 & 4.16 & -0.32 \\
b3 & 2.00 & 2.16 & 4.42 & -0.16 \\
c1 & 2.67 & 1.75 & 4.89 & 0.93 \\
c2 & 2.84 & 2.06 & 4.24 & 0.78 \\
c3 & 2.05 & 2.19 & 4.37 & -0.13 \\
d1 & 2.02 & 2.35 & 5.24 & -0.33 \\
d2 & 2.84 & 2.40 & 5.41 & 0.44 \\
d3 & 2.98 & 2.43 & 4.06 & 0.55 \\
Mean & 2.03 & 2.03 & & 0.00 \\
\hline
\end{tabular}

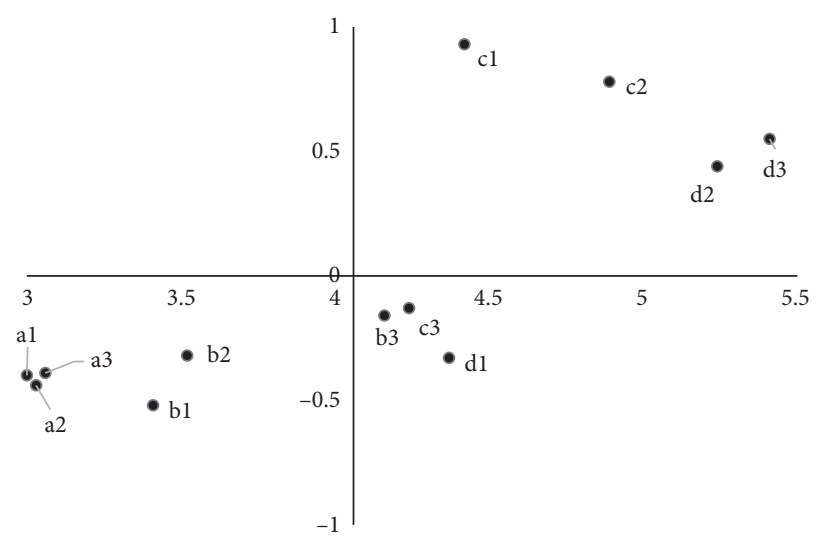

Figure 2: Influences between the 12 criteria.

TABLE 7: IPA-DEMATEL analysis of the performance and competitive strategies of company $T$ as a green hotel.

\begin{tabular}{|c|c|c|}
\hline $\begin{array}{l}\text { Competitive } \\
\text { strategy }\end{array}$ & Criteria & Analysis of competitive strategy through the DEMATEL approach \\
\hline $\begin{array}{l}\text { Keep up the good } \\
\text { work }\end{array}$ & $\begin{array}{l}\text { D3 overall service quality } \\
\text { B1 garbage classification and recycling } \\
\text { B2 prohibition of disposable products and } \\
\text { engagement in waste reduction efforts } \\
\text { C3 use of organic food products }\end{array}$ & $\begin{array}{l}\text { High-relation, high-prominence criteria, belonging in the cause group. } \\
\text { Company } T \text { should focus on maintaining its performance on these two } \\
\text { criteria to maintain its competitive advantage and enhance both its } \\
\text { green performance and its competitiveness in other criteria. } \\
\text { These three criteria are relatively independent. They do not easily } \\
\text { influence other criteria; nor are they easily influenced by other criteria. }\end{array}$ \\
\hline Concentrate here & $\begin{array}{l}\mathrm{C} 2 \text { environmental protection and } \\
\text { maintenance }\end{array}$ & $\begin{array}{l}\text { High-relation, high-prominence criteria, belonging in the cause group. } \\
\text { These key criteria influence other criteria and constitute factors driving } \\
\text { problem resolution. Therefore, company } T \text { should channel resources } \\
\text { into these criteria immediately to resolve problems regarding its green } \\
\text { performance. Failure to take action may cause the green performance } \\
\text { of company } T \text { to fall below the industry standard, behind that of its } \\
\text { competitors. } \\
\text { The only criterion in the high-relation, low-prominence category. This } \\
\text { criterion influences few other criteria, has a low degree of influence, } \\
\text { and is relatively independent of other criteria. }\end{array}$ \\
\hline Low priority & $\begin{array}{l}\text { A2 electricity conservation practices } \\
\text { D1 brand awareness }\end{array}$ & $\begin{array}{l}\text { These two criteria are relatively independent. They do not easily } \\
\text { influence other criteria; nor are they easily influenced by other criteria. }\end{array}$ \\
\hline Possible overkill & $\begin{array}{c}\text { A1 water conservation practices } \\
\text { A3 energy conservation in air conditioning }\end{array}$ & $\begin{array}{l}\text { Low-relation, low-prominence criteria that are relatively independent } \\
\text { of other criteria and do not require much investment. }\end{array}$ \\
\hline
\end{tabular}




\section{Conclusion}

The present study combined the IPA and DEMATEL into the IPA-DEMATEL model, through which the criteria and competitive strategies of green hotels were discussed.

The IPA classified criteria C1 and D3 (green product procurement and overall service quality) as being in the "keep up the good work" quadrant, indicating that they constitute advantages of company $\mathrm{T}$. Thus, the hotel should maintain its performance in these areas. The DEMATEL analysis revealed both criteria to be located in high-relation, high-prominence category; they belong in the cause group. Therefore, company $T$ should focus on and continue investing resources in these two criteria to maintain its competitive advantage, improve green performance, and enhance performance on other criteria.

Moreover, criteria C2 (environmental protection and maintenance) and D2 (brand image) were classified in the "concentrate here" quadrant, suggesting that company $T$ is at a disadvantage in these areas. DEMATEL analysis revealed both criteria to be in the high-relation, high-prominence category; they also belong in the cause group. These key criteria influence other criteria and are factors that drive problem resolution. Therefore, company $T$ should immediately channel its resources into these areas to enhance its green performance. Failure to take action may cause its green performance to fall below the industry standard and behind that of its competitors.

The present IPA-DEMATEL model can be applied in the analysis of various topics, industries, and cases, including competitive strategy analysis, facilitating the development of other criteria systems.

\section{Data Availability}

All data are included within the paper.

\section{Conflicts of Interest}

The author declares no conflicts of interest.

\section{Acknowledgments}

This work was supported by the Research Mission Fund of Minghsin University of Science and Technology (MUST110-23).

\section{References}

[1] P. C. Yesawich, "Marketing in the 1980s," The Cornell Hospitality and Restaurant Administration Quarterly, vol. 20, no. 4, pp. 38-45, 1988.

[2] H. Ayala, "Ecoresort: a "green" masterplan for the international resort industry," International Journal of Hospitality Management, vol. 14, no. 3-4, pp. 351-374, 1995.

[3] V. Belton and A. E. Gear, "The legitimacy of rank reversal-a comment," Omega, vol. 48, no. 13, pp. 227-230, 1985.

[4] D. R. Daniel, "Management information crisis," Harvard Business Review, vol. 48, no. 9, pp. 111-121, 1961.
[5] A. N. Geller, "Tracking the critical success factor for hotel companies," The Cornell Hospitality and Restaurant Administration Quarterly, vol. 2, no. 1, pp. 76-81, 1985.

[6] A. Gan, "The impact of public scrutiny on corporate philanthropy," Journal of Business Ethics, vol. 69, no. 3, pp. 217-236, 2006.

[7] E. Herrera-Viedma, F. Herrera, F. Chiclana, and M. Luque, "Some issues on consistency of fuzzy preference relations," European Journal of Operational Research, vol. 154, no. 1, pp. 98-109, 2004.

[8] E. Juholin, "For business or the good of all? A Finnish approach to corporate social responsibility," Corporate Governance: The International Journal of Business in Society, vol. 4, no. 3, pp. 20-31, 2004.

[9] J. K. Leidecker and A. V. Bruno, "Identifying and using critical success factors," Long Range Planning, vol. 17, no. 1, pp. 23-32, 1984.

[10] K. Manaktola and V. Jauhari, "Exploring consumer attitude and behaviour towards green practices in the lodging industry in India," International Journal of Contemporary Hospitality Management, vol. 19, no. 5, pp. 364-377, 2007.

[11] N. A. Tzschentke, D. Kirk, and P. A. Lynch, "Going green: decisional factors in small hospitality operations," International Journal of Hospitality Management, vol. 27, no. 1, pp. 126-133, 2008.

[12] T.-C. Wang and T.-H. Chang, "Application of consistent fuzzy preference relations in predicting the success of knowledge management implementation," European Journal of Operational Research, vol. 182, no. 3, pp. 1313-1329, 2007.

[13] X. Chi and H. Han, "Exploring slow city attributes in mainland China: tourist perceptions and behavioral intentions toward Chinese Cittaslow," Journal of Travel \& Tourism Marketing, vol. 37, no. 3, pp. 361-379, 2020.

[14] S. Moro, J. Esmerado, P. Ramos, and B. Alturas, "Evaluating a guest satisfaction model through data mining," International Journal of Contemporary Hospitality Management, vol. 32, no. 4, pp. 1523-1538, 2019.

[15] J. Wang and Z. Wang, "Strengths, weaknesses, opportunities and threats (SWOT) analysis of China's prevention and control strategy for the COVID-19 epidemic," International Journal of Environmental Research and Public Health, vol. 17, no. 7, p. 2235, 2020.

[16] R. T. R. Qiu, J. Park, S. Li, and H. Song, "Social costs of tourism during the COVID-19 pandemic," Annals of Tourism Research, vol. 84, Article ID 102994, 2020.

[17] S.-B. Tsai, C.-Y. Huang, C.-K. Wang et al., "Using a mixed model to evaluate job satisfaction in high-tech industries," PLoS One, vol. 11, no. 5, Article ID e0154071, 2016.

[18] S.-B. Tsai and K. Wang, "Using a novel method to evaluate the performance of human resources in green logistics enterprises," Ecological Chemistry and Engineering S, vol. 26, no. 4, pp. 629-640, 2019.

[19] E. Fontela and A. Gabus, The DEMATEL Observer (DEMATEL 1976 Report), Battelle Geneva Research Center, Switzerland, Geneva, 1976.

[20] A. Gabus and E. Fontela, Perceptions of the World Problematique: Communication Procedure, Communicating with Those Bearing Collective Responsibility, DEMATEL Report No. 1, Battelle Geneva Research Center, Geneva, Switzerland, 1973.

[21] J.-J. Guo and S.-B. Tsai, "Discussing and evaluating green supply chain suppliers: a case study of the printed circuit board industry in China," The South African Journal of Industrial Engineering, vol. 26, no. 2, pp. 56-67, 2015. 
[22] R. Handfield, S. V. Walton, R. Sroufe, and S. A. Melnyk, "Applying environmental criteria to supplier assessment: a study in the application of the analytical hierarchy process," European Journal of Operational Research, vol. 141, no. 1, pp. 70-87, 2002.

[23] S. Holdsworth and I. Thomas, "A sustainability education academic development framework (SEAD)," Environmental Education Research, vol. 22, no. 8, pp. 1073-1097, 2016.

[24] C. Izunildo, G. Antonio, and C. M. Virgilio, "A decisionmaking model for lean, agile, resilient and green supply chain management," International Journal of Product Research, vol. 50, no. 17, pp. 4830-4845, 2012.

[25] N. K. Jajo and J. Harrison, "World university ranking systems: an alternative approach using partial least squares path modelling," Journal of Higher Education Policy and Management, vol. 36, no. 5, pp. 471-482, 2014.

[26] C.-J. Lin and W.-W. Wu, "A causal analytical method for group decision-making under fuzzy environment," Expert Systems with Applications, vol. 34, no. 1, pp. 205-213, 2008.

[27] A. Lauder, R. F. Sari, N. Suwartha, and G. Tjahjono, "Critical review of a global campus sustainability ranking green metric," Journal of Cleaner Production, vol. 108, pp. 852-863, 2015.

[28] Y. C. Lee and Y. F. Hsieh, "Integration of revised simultaneous importance performance analysis and decision making trial and evaluation laboratory-a study of mobile telecommunication industry in Taiwan," African Journal of Business Management, vol. 5, no. 6, pp. 2312-2321, 2011.

[29] H. F. Moed, "Critical comparative analysis of five world university rankings," Scientometrics, vol. 2016, 24 pages, 2016.

[30] R. Scott, "Education for sustainability through a photography competition," Sustainability, vol. 6, no. 2, pp. 474-486, 2015.

[31] N. Suwartha and R. F. Sari, "Evaluating UI GreenMetric as a tool to support green universities development: assessment of the year 2011 ranking," Journal of Cleaner Production, vol. 61, pp. 46-53, 2013.

[32] W.-W. Wu and Y.-T. Lee, "Developing global managers' competencies using the fuzzy DEMATEL method," Expert Systems with Applications, vol. 32, no. 2, pp. 499-507, 2007.

[33] W.-W. Wu, "Segmenting critical factors for successful knowledge management implementation using the fuzzy DEMATEL method," Applied Soft Computing, vol. 12, no. 1, pp. 527-535, 2012. 